\title{
The road user behaviour of school students in Belgium
}

\author{
Mark J.M. Sullman*, Abigail Thomas** \& Amanda N. Stephens\# \\ *Cranfield University, UK \\ **University of Hertfordshire, UK \\ \# University College Cork, Ireland
}

\begin{abstract}
The present study aimed to investigate both the on road behaviour of Belgian school students and the validity of the Adolescent Road User Behaviour Questionnaire (ARBQ) in a sample of students attending school in Belgium. In total, 294 adolescents completed the ARBQ along with measures of their self-reported accident involvement and sensation seeking behaviour. Confirmatory Factor Analysis supported the original factor structure of: "Unsafe road crossing", "Playing on the road" and "Planned protective behaviour" for the 21-item version of the questionnaire, but not for the full scale. Males were found to engage more often in unsafe crossing behaviour and playing on the roads. There were also age differences, with unsafe road crossing increasing with age and engagement in planned protective behaviours improving with age. Those who reported being involved in an accident also reported more frequent engagement in unsafe crossing, playing on the roads, thrill seeking behaviour and lower levels of behaviour inhibition. Therefore, this study confirms that the ARBQ is a useful tool for investigating safety-related behaviours that contribute to accident involvement.
\end{abstract}

Keywords: Adolescents, Behaviour, Pedestrians, ARBQ, Road Safety 


\section{Introduction}

Unintentional injury is the principal cause of death amongst children and adolescents in all of the developed nations (UNICEF, 2001). This is also the case in Belgium, which has one of the less enviable child safety records in Western Europe. In 2007, out of the $18 \mathrm{EU}$ countries that participated in the Child Safety Action Plan, Belgium had the sixth highest death rate for males under 19 years old and the ninth highest for females (European Child Safety Alliance, 2007). As is the case in most other developed countries, road traffic accidents in Belgium account for the single largest proportion of deaths. For young males, there are almost eight times as many deaths due to traffic accidents than for any other cause. Furthermore, traffic accidents are also by far the largest cause of accidental death among young females (European Child Safety Alliance, 2007). One important first step in improving the safety of Belgium adolescents is to understand the behaviours that may put them at an increased risk of being killed or injured on the road.

Unlike the area of risky driving behaviour, there is currently no agreed upon framework for investigating the pedestrian behaviour of children or adolescents. However, one recently developed framework for investigating the on-road behaviour of adolescents, in relation to accident involvement, is the Adolescent Road-user Behaviour Questionnaire (ARBQ) (Elliott \& Baughan, 2004). The ARBQ was developed by Elliott and Baughan (2004) and is based upon information collected from focus groups and police descriptions of pedestrian accidents involving adolescents. The questionnaire measures the on-road behaviour of adolescents as pedestrians, while also including a small number of other important behaviours, such as cycling, skateboarding and rollerblading on the road. Elliott and Baughan (2004) studied 2433 English students aged between 11-16 years old using the 43-item ARBQ and found that the data produced three reliable factors. These were labelled: "unsafe crossing behaviour" (e.g. getting part way across the road and having to turn back to avoid traffic); "dangerous playing in the road" (e.g. playing football on the road); and "planned protective behaviour" (e.g. using lights when riding a bike). In addition, this research also developed a 21-item version of the scale, which also had good internal reliability.

The three ARBQ factors were also largely supported by a follow-up study conducted in New Zealand (Sullman \& Mann, 2009). Sullman and Mann obtained data from 944 New Zealand school students and largely reproduced the three-way distinction, using exploratory factor analysis, for both the long and short versions of the scale. However, as both the United 
Kingdom and New Zealand are English speaking countries with relatively similar cultures, Sullman and Mann (2009) recommended research be conducted in a more culturally different, non-English speaking country. This was attempted in a recent study using students from Spain, where over 2000 Spanish school students completed the ARBQ (Sullman, Gras, FontMayolas, Masferrer, Cunill \& Planes, 2011). Confirmatory Factor Analysis found that although the long version of the scale did not adequately describe the data, the short version provided an adequate fit for the three factor model. Therefore, the factor structure of the ARBQ has reasonable support and the three factors have been shown to be replicable across three different countries and cultures.

Although there are considerable differences between New Zealand, England and Spain regarding the road traffic surroundings (for example, the population density, climate, geography and ethnic composition), there were also many similarities in the findings using the ARBQ. For example, in all three studies males reported playing on the road significantly more than females (Elliott \& Baughan, 2004; Sullman \& Mann, 2009; Sullman et al., 2011). Furthermore, in two of the three studies males reported engaging in more unsafe crossing behaviours than females. No gender differences were found in the planned protective behaviour factor in any of the three studies (Elliott \& Baughan, 2004; Sullman \& Mann, 2009; Sullman et al., 2011).

The relationship the three ARBQ factors had with age have also shown reasonable consistency, particularly between the UK and Spanish studies. In both the Spanish and UK studies age differences were found for all three factors, with unsafe road crossing increasing with age, while playing on the roads and planned protective behaviours both decreased with age. Unfortunately the NZ study did not include any students in the 11-12 age group, making a comparison with the other two studies problematic.

In addition to gender and age there is some support for there being ethnic differences in the on-road behaviour of school students. For example, in Sullman and Mann's (2009) research it was reported that those who were even part Maori (native people of NZ) were found to be more likely to put themselves at risk by playing on the road and engaged more frequently in unsafe road crossing behaviours. These findings were not supported by Elliott and Baughan (2004), which can be put down to differences in the ethnic composition of the 
three samples. Unfortunately in the Spanish study ethnicity was not measured, as the students were almost exclusively Spanish Europeans (Sullman et al., 2011).

Another area where there have been inconsistent findings are the relationships the ARBQ factors have with the students' place of residence. Elliott and Baughan (2004) found that adolescents from rural areas reported engaging less frequently in dangerous crossing behaviours and more frequently in planned protective behaviours, than their urban counterparts. However, surprisingly, rural adolescents reported more playing on the roads than those from urban areas. Perhaps the reason for this finding is that in urban areas in England it may simply not be possible to play on the roads. Unfortunately, in the Spanish study, the adolescents were all from one urban area and rural adolescents were not included, while the NZ research did not replicate the English findings. Perhaps the reason for this is that $\mathrm{NZ}$ is a much less densely populated country, meaning that what constitutes a rural or urban area may be different from those in Europe. Indeed, using the criteria used by Elliott and Baughan to describe a small urban area (less than 125,000 inhabitants), NZ has only three cities that fall outside this criterion.

Interestingly, although the ARBQ measures risky behaviours that are thought to be related to accident involvement, none of the three previous studies actually measured accident involvement. This is particularly surprising as these studies were all investigating types of behaviours believed to increase or decrease involvement in accidents. Another important gap is the psychological precursors that lead school children to behave in a risky manner on the road. Although it is important to understand the behaviours that are related to accident and injury involvement, it is also useful to understand the psychological mechanisms underpinning these behaviours. This in turn, may help understand how best to influence road user behaviour. Although there are many personality variables that may be related to risky behaviour on the road, one which has been found to be very important in the safety field is sensation seeking (e.g. Zuckermann, 1994). Adults and adolescents high in sensation seeking have been found to engage in greater physical and health-related risk behaviours (Arnett et al., 1997; Zuckermann, 1994). However, although the relationship between sensation seeking and risk taking is well established in adults and adolescents, very little research has been conducted with children (Morongiello \& Lasenby, 2006). In one of the few studies to investigate sensation seeking in children, Morongiello and Lasenby found sensation seeking to be significantly related to a number of indices of risk taking behaviour. Therefore, 
investigating the relationship sensation seeking behaviour has with school students' on-road behaviour would appear to be warranted.

The present study therefore investigated the relationship sensation seeking behaviour has with the ARBQ factors, along with the ARBQ's ability to describe the on-road behaviour of adolescents attending school in Belgium. The study also attempted to confirm the threeway distinction in both the long and short versions of the scale and to test for differences by age, sex, ethnicity and place of residence. Finally, the present study investigated whether any of the ARBQ factors were related to self-reported accident involvement on the road.

\section{Method}

\subsection{Participants}

This survey was undertaken in two schools in the town of Waterloo, Belgium. The first school was a private International English-speaking school for children between the ages of 11 and 17. There were a total of 39 nationalities attending this school. The second school was a public French-speaking school with children aged 15 to 19 years. The children at this school completed the questionnaire in English during English class.

In total, 280 students were asked to complete the questionnaire from the International school, although 265 students actually completed it producing a response rate of $94.6 \%$. A total of 60 students from the French-speaking school were requested to fill in the questionnaire, with only 29 students completing it (a response rate of 48.3\%). This resulted in 294 students from both schools completing the questionnaire, out of a possible 340 (an overall response rate of $86.5 \%$ ). In total there were 148 males and 146 females with a mean age of $13.55(\mathrm{SD}=2.09)$ and a range of 11 to 19 years.

Most of the students (251) stated that they did not possess a driving license, sixteen students stated that they had a provisional license, one student possessed a restricted license and seven students possessed a full driving licence (19 participants did not report their licence status). Most students (204) reported living in a small town, 59 participants stated they lived in a city, and 30 participants lived in a small village (one student did not report their residence). 
The most common nationality was American (19.4\%), followed by Belgian (16.7\%), British (9.2\%) and Swedish (5.7\%) The remaining 49.2\% were either combinations of different nationalities (e.g. Belgian/Spanish) or small numbers from other countries (e.g. Australia, Ethiopia, Korea, India). Participants were also asked whether they had been involved in an accident on the road; 53 students reported that they had been involved in an accident on the road. Some of the examples included; "I have been hit by a car outside school, and I also crashed into a truck"; "I was on my bike when it was icy. I fell near a round-a-bout but there was no big injury, just a bruise". The remaining 239 students stated that they had not been involved in an accident on the road.

[Insert Table 1]

\subsection{Materials}

The questionnaire contained a number of demographic questions, including: age, sex, nationality, ethnic background, school grade, area of residence, licence status (only answered by students above the age of 15) and whether they had been previously involved in an accident on the road. The questionnaire also included the ARBQ (Adolescent Road-User Behaviour Questionnaire), and the Sensation Seeking Scale for adolescents.

\subsubsection{ARBQ (Adolescent Road-User Behaviour Questionnaire)}

The students completed the ARBQ (Adolescent Road-User Behaviour Questionnaire) (Elliot \& Baughan 2004). The ARBQ is a self-report questionnaire investigating how often participants engage in 43 different road-user behaviours. For example, "How often do you not look because you can't hear any traffic coming?". The responses were made using a five point Likert Scale $(1=$ Never to $5=$ Very often). Previous research has indicated that the 43 items could be grouped into three subscales; "planned protective behaviour", "playing on the road" and "unsafe road crossing behaviour". These three factors had internal reliability scores of $.89, .85$ and .76 , respectively.

\subsection{Sensation Seeking Scale for Children}

The Sensation Seeking Questionnaire for children (Morrongiello \& Lasenby, 2006) was also used in this research. The questionnaire is comprised of 27 questions which measure three aspects of sensation seeking, which are; Thrill Seeking, Behavioural Intensity and Inhibitory Control. The questions were designed to be appropriate for 7 to 12 year olds and 
were answered on a five point Likert scale ( $1=$ Strongly agree to $5=$ Strongly disagree). The internal reliability for each subscale were also good, being .78 for Behavioural Intensity, .79 for Behavioural Inhibition and .79 for Thrill Seeking.

\subsubsection{Procedure}

The head teachers from the participating schools were contacted for permission to conduct the survey. Once permission was granted from both head teachers; parent/guardian consent forms and information sheets were sent to students' parents or guardians. This allowed parents to understand the purpose of the research and invited them to withdraw their child from the study, if they so wished, by completing a withdrawal form and returning it to the school. Only the students whose parents did not return their consent form completed a questionnaire. The participants were also presented with an information sheet before they filled out the questionnaire, offering them the opportunity to withdraw from the study if they chose to do so. They were also given a debrief sheet after they had completed the questionnaire, stating that the students or parents may make contact if they wanted details of the findings or to withdraw their data if they so wished. The students completed the questionnaires during normal class hours, and were informed that all responses provided would remain completely anonymous and confidential. Students answering the questionnaire online completed it in a school computer laboratory during normal school hours.

In an attempt to avoid potential order effects two versions of the questionnaire were used. In the first version the ARBQ was presented first, followed by the Sensation Seeking Scale. In the second version of the questionnaire, the sensation seeking scale was presented before the ARBQ. An equal number of children were requested to complete each of the two formats; resulting in 149 students completing the questionnaire with the ARBQ first and 145 children completing the version with the Sensation Seeking Scale first. Independent t-tests adjusted for multiple comparisons showed no reliable difference in ARBQ or sensation seeking scores, according to presentation order. In both versions of the questionnaire the two scales were preceded by demographic questions including; age, sex, school grade, nationality, residence and previous accidents on the road. The questionnaire was available online, hosted by Bristol Online Surveys and in paper format to accommodate each classroom's requirements. In total 187 students completed the questionnaires online and 107 students completed a printed version of the questionnaire. 
The time required to complete the questionnaire was about 20 to 25 minutes, depending on the student's reading ability and their ability to comprehend English. Some students from the middle school required an explanation of certain questions in the ARBQ (Adolescent Road-User Behaviour Questionnaire), for example; "how often do you play "chicken" by lying down on the road and wait for cars to come along?". In addition to this, many of the French-speaking students from the French school requested explanations and examples (in French) for some questions they found difficult to understand.

\section{Results}

Before any analysis of the data was completed, the scores for the Planned Protective Behaviour items were reversed so that a score of "1" represented "good" behaviour, as was the case for the other ARBQ items. In order to maximise data retention, mean item replacement was used where there were one to three missing items on the ARBQ or Sensation Seeking Scale. This process was only undertaken for the 107 questionnaires that were completed in hard copy, as there was no missing data for the 187 questionnaires collected online.

\subsection{Mean comparison between Belgium, New Zealand, Spain and England}

Table 2 represents the means, standard deviations and rankings (shown in descending order according to the Belgium mean), for all 43 ARBQ items. The three columns titled "New Zealand", "England" and "Spain" illustrate the means, standard deviations and rankings for the matching 43 items measured in the New Zealand research (Sullman and Mann, 2009); the Spanish research (Sullman et al., 2011) and the UK research (Elliott and Baughan, 2004). This table shows that the behaviour "Look both ways before crossing" had the highest mean in the Belgian, New Zealand, English and Spanish samples. Following this, the second highest ranked mean for Belgium, England, New Zealand and Spain was "Check to make sure traffic has stopped before using a pedestrian crossing". In fact, the top five behaviours reported were similar for all four countries, with each of the three other countries having four out of the five most frequently reported behaviours in Belgium. 
However, the most obvious differences in the ranking of items were with; "Wear a cycle helmet when riding a bike" and "Using a crossing monitor where there is one available”. In Belgium they were ranked fourth and seventh, fourth and third in New Zealand, $26^{\text {th }}$ and $27^{\text {th }}$ in England and in Spain they were ranked sixth and $26^{\text {th }}$. This shows that children from the UK and Spain are less likely to wear a helmet when riding a bike compared to children in Belgium and New Zealand. In addition, children in the UK appear to be much less likely to use a crossing monitor than children from Belgium, Spain and New Zealand.

There were also similarities in the least frequently reported behaviours, with the five least frequently reported behaviours in Belgium and New Zealand including the same five items (although, not with the same order), and four of the five least frequently reported behaviours were also the same in Spain and England.

[Insert Table 2]

\subsection{Confirmatory Factor Analysis on the Adolescent Road User Behaviour Questionnaire}

EQS v.6.1 for windows (Bentler, 2005) was used to conduct Robust Maximum Likelihood (ML) confirmatory factor analyses to test two competing models of the ARBQ : the three factor model comprising 43 items originally proposed by Elliot and Baughan (2004) against the three factor 21 item model also proposed by Elliot and Baughan and supported by Sullman et al. (2011). Five cases were deleted from the original data set to improve overall kurtosis. As Mardia's normalised estimate was above 5, suggesting non-normally distributed data (Bentler, 2005) goodness of fit indices were taken from the Robust ML estimates. Model fit was evaluated with the Santorra-Bentler Scales Chi-Squared (S-B $\left.\chi^{2}\right)$, adjusted Comparative Fit Index (CFI) and Root Mean Square Error of Approximation (RMSEA). Acceptable model fit was indicated by an adjusted CFI of .90 or greater and an RMSEA of .60 or less (Hu \& Bentler, 1999). The confidence interval (C.I.) reporting a $90 \%$ interval surrounding the RMSEA and Bozdogan's (1987) consistent version of Akaike's (1987) Information Criteria (CAIC) was also examined. The latter takes into account sample size and provides information on a comparison between two models, with smaller values representing better fit of the hypothesised model (Hu \& Bentler, 1995).

Table 3 summarises the goodness of fit indices for the two models. The 43-item three factor model produced poor goodness of fit indices. Lagrange Multiplier (LM) Test identified several misfitting parameters, mainly concerned with error covariances. When the model was 
respecified with 11 pairs of errors covaried, seven of which are the same pairs covaried in Sullman et al. (2011) and one crossloaded factor, the goodness of fit indices were improved, but still did not offer an acceptable representation of the data. The 21-item three factor model did show an adequate fit to the data when the original model (third model fitted) was respecified to covary nine pairs of errors. Respecification was determined using the results of the Lagrange Multiplier (LM) Test, with six of the nine error covariances being the same pairs covaried for best model fit by Sullman et al. (2011; see Figure 1 which also highlights correlation coefficients between covaried errors).

[insert Table 3 about here]

[insert Figure 1 about here]

Figure 1 outlines the factor loadings, which are similar to the Spanish sample reported in Sullman et al. (2011) and were all statistically significant (ps<.001). With the exception of Item 27 "Ride on a skateboard (or roller-skates/roller-blades) on the road", which had a fairly weak loading on Playing on the Road, all items had a factor loading > .30. The three factors of: Unsafe Crossing behaviour, Playing on the Road and Planned Protective Behaviour all exhibited good construct reliability (>.70). Intercorrelations between the three factors are also presented on Figure 1. These were all in the low to moderate range (.17 to .51$)$. Average error variances for each construct were calculated and found to be higher than the squared intercorrelation coefficients, thus confirming the discriminant validity (Fornell and Larcker, 1981) of the three constructs. All resultant analyses were performed on the 21-item three factor model.

\subsubsection{Adolescent Road-User Behaviour by gender}

Table 4 shows gender differences in self-reported road-user behaviour across the three ARBQ factors. Males reported more unsafe crossing behaviours $(\mathrm{p}<.001)$ and higher levels of playing on the roads $(\mathrm{p}<.01)$ than females. However, no gender differences were apparent for the planned protective behaviour scores.

[insert Table 4 about here]

\subsubsection{Adolescent Road-User Behaviour by age group}

There were also broad age differences, with unsafe crossing behaviour increasing with age and planned protective behaviours improving with age (Table 5). Specifically, those in the 
11 to 12 year age group reporting reliably more safe crossing behaviour than the other two age groups $(\mathrm{p}<.001)$. Scores on crossing behaviour were statistically similar for the 13 to 14 year old group and the 15 years and older group. Adolescents aged between 13 and 14 years old had reliably higher scores for playing on the road when compared to the 15 and over group $(\mathrm{p}<.01)$, but their scores did not differ significantly from their younger counterparts aged 11 to 12 . Reported planned protective behaviours improved with age $(\mathrm{p}<.001)$. Young adolescents aged 11 to 12 reported the lowest levels of planned protective behaviour, followed by 13 to 14 year olds and both these groups had statistically different scores on this factor when compared to the adolescents 15 years and older.

[insert Table 5 about here]

\subsubsection{Adolescent Road-User Behaviour by area of residence and ethnic group}

There were no differences in reported road-user behaviours according to area of residence. Table 6 shows that adolescents classifying themselves as of "other" ethnicity reported more unsafe crossing behaviours than European or Asian adolescents $(p<.01)$. A reliable effect of ethnic group on both, levels of dangerous playing on the road ( $p<.05$ ), and planned protective behaviour were found. Adolescents classifying themselves as of European ethnicity reported higher levels of dangerous play on the road and less planned protective behaviour than those of "other" ethnicity.

[insert Table 6 about here]

\subsubsection{Sensation Seeking Factor analysis}

The Sensation Seeking questionnaire (SS) included a total of 27 questions. The data were factor analysed with the scree plot and the results of a parallel analysis suggesting that two factors would best represent the data. The analysis was rerun specifying two factors. The two Factors contained $37.2 \%$ of the variance, with Factor 1 accounting for $26.7 \%$ of the variance and consisting of items from the "Behavioural Intensity" and "Thrill Seeking" subscales (Morrongiello \& Lasenby, 2006) (Table 7). Factor 2 accounted for $10.5 \%$ of the variance and was named "behaviour inhibition" as it included items exclusively from the original behavioural inhibition subscale. There were no cross loadings (.300 or above) and the factors had internal reliability of .90 and .73 , respectively. 
[Insert Table 7]

\subsection{Previous Accidents, Sensation Seeking and the ARBQ}

Table 8 shows the level of sensation seeking behaviour and on-road behaviour according to previous accident involvement. Adolescents who reported previously being involved in an accident reported more thrill seeking behaviour, more unsafe road crossing behaviours, more dangerous playing on the road and less behavioural inhibition than those with no accident history. However, surprisingly adolescents previously involved in an accident also reported more planned protective behaviours than those with no accident history.

Table 9 shows the relationships between the three ARBQ factors, Sensation Seeking, age and previous accidents. Age was positively related to unsafe crossing behaviour but was negatively related to planned protective behaviour. Adolescents previously involved in a higher number of accidents reported higher levels of dangerous playing on the road, more unsafe crossing behaviours and less planned protective behaviours. Higher levels of thrill seeking were related to more playing on the road, more unsafe road crossing behaviours and less planned protective behaviour. Lower tendencies for behaviour inhibition was reliably related to less planned protective behaviours, along with more dangerous playing on the road and unsafe crossing behaviours.

\subsubsection{Sensation Seeking and gender, age, area of residence and ethnic group}

Table 10 shows the sensation seeking scores by gender. Males reported more thrill seeking behaviours and less inhibition behaviours than females. Sensation seeking scores also differed according to age group. Table 11 shows that younger adolescents reported more inhibition behaviours than adolescents aged 13 to 14 years. Sensation seeking scores did not differ according to area of residence. Table 12 shows that thrill seeking scores differed by ethnic group. European adolescents reported reliably more thrill seeking behaviours than Asian adolescents.

\section{Discussion}

The present study investigated the road user behaviour of adolescents attending school in Belgium and made a number of findings consistent with previous research conducted in NZ, Spain and the UK. Firstly, there were considerable similarities in the ranking, by mean, of the 43 different behaviours across the four countries. For example, four of the five most 
frequently reported behaviours by the present sample were also in the top five for NZ, Spain and the UK. Moreover, while the five least frequently engaged in behaviours were the same as in NZ, four of the five were also the same in the UK and Spain.

The relationships the ARBQ factors had with the demographic variables also showed similarities with the previous research. In the present study, males reported more playing on the roads and unsafe road crossing behaviour, than females, while there was no difference on the planned protective behaviour factor. These findings are in accordance with those found in the UK and Spain (Elliott \& Baughan, 2004; Sullman et al., 2011), and were mostly similar to those from NZ (Sullman \& Mann, 2009). The only difference in the NZ research was that they found no sex differences in the unsafe crossing behaviour factor. As NZ was the only non-EU country, perhaps there are some cultural or geographic reasons for this incongruent finding. Therefore it can be broadly suggested that it is male adolescents that are most likely to engage (or not engage) in on-road behaviours that put themselves at risk of being killed or injured. This finding agrees with research using different instruments to measure on-road behaviour (e.g. Byrnes, Miller \& Schafer, 1999; Granié, 2007; Morrongiello \& Dawber, 1999; Waylen \& McKenna, 2008; West et al., 1998) and accident statistics (e.g. BRAKE, 2004; European Child Safety Alliance, 2007; European Commission, 2008; European Commission, 2010; Poudel-Tandukar et al., 2006; UNICEF, 2001).

The present study also investigated the relationship between self-reported accidents and the ARBQ factors. As would be expected, given the aim of the scale, students who reported being previously involved in an accident also reported more frequently engaging in unsafe crossing behaviour and playing on the road, but surprisingly engaged more frequently in planned protective behaviours, than those who had not been accident involved. Although the ARBQ was developed using accident data and specialist knowledge from safety experts, the present research is the first to confirm the relationship the scale has with accident involvement. This finding therefore provides some evidence of the scale's criterion-related validity. Given the relationship between the ARBQ factors and accident involvement, it could be argued that safety improvements could be made by making positive changes in the behaviours measured by the scale. Furthermore, the present research also highlights the potential of the ARBQ for tracking the impact of any interventions aimed at improving school students' on-road behaviour. Future research should be undertaken to confirm this. However, as both the ARBQ and accidents were self-reported, there is a risk that common method 
variance may be in operation. Therefore, future research should be undertaken to confirm these findings using accident data from another source, such as school records, police records or reported by their parents.

This study also tested whether the original three factor solution for the long and short versions of the ARBQ would be supported in this sample of students attending school in Belgium. CFA found satisfactory fit indices for the 21-item version of the scale, but not the 43-item version. Interestingly this replicates the findings of Sullman et al. (2011), which collected data from Spanish school students. Using CFA Sullman et al. found satisfactory fit indices for the shortened version of the scale but not the 43-item version. Although it is disappointing not to obtain a satisfactory fit for the 43-item scale, the 21-item scale is perhaps more practical, as the lower number of items allows the scale to be more readily combined with other research instruments. The three-way distinction has now been shown to be stable across four different countries and cultures. Nevertheless, one common factor in all four countries is that they are mostly European-based cultures. Therefore, future research is needed to investigate whether similar findings will be made in a non-European based culture.

The relationship the three ARBQ factors had with age were also similar to those found amongst English and Spanish school students (Elliott \& Baughan, 2004; Sullman et al., 2011). The present study found unsafe crossing behaviour increased with age, as was found in both the Spanish and English studies. Furthermore, as in the present study, engagement in planned protective behaviour decreased with age in both the English and Spanish studies. Finally, the pattern for playing on the road was also similar to that found in the UK, with both the present study and Elliott and Baughan finding a peak in the 13-14 year age group. Although this appears to contrast with the findings in Spain and NZ, the Spanish research used slightly different age groups, while the NZ research used individual ages and did not include students younger than 13 years old. Therefore, the overall pattern is for an increase in risky behaviours, which could be due to the fact that at this time in their lives the students are becoming more independent from their parents and are more frequently exposed to risk (Lynam \& Harland, 1992; Morrongiello \& Barton, 2009).

One area where the ARBQ results have not been consistent is in regard to the ARBQ factors' relationships to ethnicity. The present study found that European and Asian students reported less unsafe crossing behaviour, compared to those who classified themselves as 
"other". In addition, Europeans also reported lower levels of playing on the road and were less likely to engage in planned protective behaviours than those classified as "other". However, care should be taken when interpreting these figures, as the non-European categories contained very few participants (i.e. Asian $=29$, Other $=22$ ). Nevertheless, this study does provide some support for the findings in Sullman and Mann's (2009) research, in that both studies found ethnic minorities engaged more often in unsafe crossing behaviour and dangerous playing on the road. However, in contrast to the NZ research, the present study found that Europeans engaged less often in planned protective behaviour. Although Sullman et al. (2011) did not measure ethnicity, Elliott and Baughan (2004) found no differences in onroad behaviour by ethnicity. These inconsistent findings could, of course, be due to differences in the ethnic compositions of the four countries, as although all four are mostly European, those in the minority groups may differ substantially. For example, Maori and Polynesians are the second and third most common ethnic groups in NZ, but are unlikely to be common in England, Spain or Belgium.

The present study also found the sensation seeking scale of Morrongiello and Lasenby (2006) had only two reliable factors. In this case the "behavioural intensity" sub-scale and the "thrill seeking" sub-scale loaded on one factor. This finding does not conflict with the findings of Morrongiello and Lasenby, as they did not subject their data to factor analysis. Furthermore, given the definitions of thrill seeking (prefer activities that are emotionally arousing and evoke excitement) and behavioural intensity (prefer behaviourally intense activities), along with the types of items which each scale is comprised of (e.g. Behavioural Intensity - "I am the sort of person who would find it exciting to do risky sports" and "I wouldn't be afraid to climb to the very top of a tall ladder" versus Thrill Seeking - "I would like to try jumping from a plane with a parachute" and "I sometimes like to do things that are a little scary") it is not too surprising that these loaded together. Therefore, it appears that the sensation seeking scale consists of two distinct and reliable constructs, thrill seeking and behavioural inhibition.

As would be expected from previous findings among adults and adolescents, the present study found that the two types of sensation seeking behaviour were significantly related to adolescents' on road behaviour. Those with lower levels of thrill seeking behaviour were less likely to engage in unsafe crossing behaviour and playing on the road, but were also less inclined to engage in planned protective behaviours. Furthermore, those low on 
behavioural inhibition were less likely to engage in planned protective behaviours and more likely to engage in playing on the road and unsafe crossing behaviours. This finding clearly supports previous research that has shown sensation seeking behaviour to be related to other types of risky behaviours in children (e.g. Morrongiello \& Lasenby, 2006) as well as adolescents and adults (e.g. Arnett et al., 1997; Zuckerman, 1994). Also as expected, given previous research (e.g. Morrongiello \& Rennie, 1998), males were more likely to report thrill seeking behaviour and were less capable of demonstrating behavioural inhibition. Clearly, both the research findings and the accident statistics again highlight the need for interventions to reduce the impact of sensation seeking on young males' risk behaviours and safety.

This research had a number of methodology limitations. Firstly, the most apparent limitation was providing questionnaires to participants in English, which may have resulted in misunderstandings. However, as the researcher and/or English teacher were available to answer questions, this is unlikely to have created a large problem. Further confidence in the students' ability to understand comes from the fact that many of the results supported previous findings from the UK, Spain and NZ.

As the present sample was sourced from a very small area of Belgium, it is likely that this sample is not representative of the different regions of Belgium. Furthermore, as can be seen from the reported nationalities, just under $17 \%$ of the participants identified themselves as Belgian only (a small number also chose Belgian and another nationality). This area of Belgium has a large number of international organisations (e.g. NATO) and workers who are posted from abroad. Therefore, this sample may not be representative of Belgian adolescents. Nevertheless, as these individuals live and attend school in the area, they are still an important part of the residents in the area and are potentially in danger of becoming a Belgian road statistic.

\section{Conclusions}

The present research further validated the ARBQ as a useful measure of adolescents' on-road behaviour. In most respects the results were similar to those found among New Zealand, English and Spanish adolescents, demonstrating the applicability of the scale to several different countries, cultures and languages. The present study confirmed the factor structure of the 21-item version of the scale and found that males were more likely, than females, to engage in unsafe road crossing behaviour and to play on the road. There was also 
a pattern of undesirable behaviours increasing with age, confirming previous findings from England and Spain. Finally the present study found that students who had been involved in an accident on the road reported higher levels of sensation seeking behaviour, engaged more often in playing on the road and also engaged more often in dangerous crossing behaviour. Overall the present study has shown that the ARBQ is a useful framework for investigating the behaviour of school students on the road. 


\section{References}

Akaike, H. (1987). Factor Analysis and AIC. Psychometrika, 52, 317-332.

Arnett, J., Offer, D., \& Fine, M. (1997). Reckless driving in adolescence: 'state' and 'trait' factors. Accident Analysis and Prevention, 29, 57-63.

BRAKE (2004). Hard facts - statistics and research: Survey of 11-14 year olds. (http://www.brake.org.uk/)

Bentler, P.M. (2005). EQS for 6 Structural equations program manual. Encino, CA: Multivariate Software.

Bozdogan, H. (1987). Model selection and Akaike's information criteria (AIC): The general theory and its analytical extensions. Psychometrika, 52, 345-370.

Byrnes, J., Miller, D., \& Schafer, W. (1999). Gender differences in risk taking: A metaanalysis. Psychological Bulletin, 125, 367-383.

Elliott, M.A., \& Baughan, C.J. (2004). Developing a self-report method for investigating adolescent road user behaviour. Transportation Research Part F, 7, 373-393.

European Child Safety Alliance (2007). Child Safety Country Profile: Belgium. Retrieved $13^{\text {th }}$ of May 2011 from the World Wide Web.

http://www.oivocrioc.org/files/nl/3070BELGIUMCPWEB.pdf

European Commission (2008). Road Safety Scoreboard. Retrieved July 72008 from the

World

Wide

Web

http://ec.europa.eu/transport/roadsafety_library/scoreboard/scoreboard.pdf

European Commission (2010). Road Safety: Commission outlines measures to halve road deaths by 2020. Retrieved $13^{\text {th }}$ of May 2011 from the World Wide Web.

http://europa.eu/rapid/pressReleasesAction.do?reference=IP/10/970\&format=HTML\&a

ged $=0 \&$ language $=\mathrm{EN}$ 
Fornell, C., and D.F. (1981). Evaluating Structural Equation Models with Unobservable Variables and Measurement Error. Journal of Marketing Research, 18, 39 - 50.

Granié, M-A. (2007). Gender differences in preschool children's declared and behavioural compliance with pedestrian rules. Transportation Research Part F, 10, 371-382.

Hu, L-T., \& Bentler, P.M. (1995). Evaluating model fit, In R.H. Hoyle (Ed.), Structural equation modelling: Concepts, issues, and applications (pp. 76-99). Thousand Oaks, CA: Sage.

Lynam, D., \& Harland, D. (1992). Child pedestrian safety in the UK. Berlin: VTI/FERSI Conference.

Morrongiello, B.A., \& Barton, B.K. (2009). Child pedestrian safety: Parental supervision, modelling behaviours, and beliefs about child pedestrian competence. Accident Analysis and Prevention, 41, 1040-1046.

Morrongiello, B., \& Dawber, T. (1999). Parental influences on toddlers' injury-risk behaviors: Are sons and daughters socialised differently? Journal of Applied Developmental Psychology, 27, 227-251.

Morrongiello, B., \& Lasenby, J. (2006). Finding the daredevils: Development of a Sensation Seeking Scale for children that is relevant to physical risk taking. Accident Analysis and Prevention, 38, 1101-1106.

Morrongiello, B.A., \& Rennie, H. (1998). Why do boys engage in more risk taking than girls? Journal of Pediatric Psychology, 23, 33-43.

Poudel-Tandukar, K., Nakahara, S., Ichikawa, M., Poudel, K.C., \& Wakai, S. (2006). Relationship between mechanisms and activities at the time of pedestrian injury and activity limitation among school adolescents in Kathmandu, Nepal. Accident Analysis \& Prevention, 38, 1058-1063. 
Sullman, M. J. M., Gras, M.E., Font-Mayolas, S., Masferrer, L., Cunill, M., \& Planes, M. (2011). The Pedestrian Behaviour of Spanish Adolescents. Journal of Adolescence, 34, 531-539.

Sullman, M.J.M., \& Mann, H. (2009). Adolescent Road User Behaviour amongst New Zealand Adolescents. Transportation Research Part F, 12, 494-502.

UNICEF. (2001). A League Table of Child Deaths by Injury in Rich Nations. Retrieved July 102008 from the World Wide Web http://www.unicef-icdc.org

Waylen, A.E., \& McKenna, F.P. (2008). Risky attitudes towards road use in pre-drivers. Accident Analysis \& Prevention, 40, 905-911.

West, R., Train, H., Junger, M., Pickering, A., Taylor, E., \& West, A. (1998). Childhood accidents and their relationship with problem behaviour. DETR Report No 7. London: The Stationery Office.

Zuckerman, M. (1994). Behavioral Expression and Biosocial Bases of Sensation Seeking. New York: Cambridge University Press. 
Table 1

Descriptives and Frequencies

\begin{tabular}{|c|c|c|c|}
\hline Participant & Frequency & Percentages (\%) & Mean (SD) \\
\hline \multicolumn{4}{|l|}{ Gender } \\
\hline Males & 148 & 50.43 & \\
\hline Females & 146 & 49.66 & \\
\hline \multicolumn{4}{|l|}{ Area } \\
\hline City & 59 & 20.07 & \\
\hline Small Town & 204 & 69.39 & \\
\hline Small Village & 30 & 10.20 & \\
\hline \multicolumn{4}{|l|}{ Nationality } \\
\hline American & 57 & 19.39 & \\
\hline Belgium & 49 & 16.67 & \\
\hline British & 27 & 9.18 & \\
\hline Swedish & 15 & 5.70 & \\
\hline Other & 146 & 49.20 & \\
\hline Age & & & $13.55(2.09)$ \\
\hline $11-12$ & 113 & 38.44 & \\
\hline $13-14$ & 86 & 29.25 & \\
\hline $15+$ & 95 & 32.31 & \\
\hline \multicolumn{4}{|l|}{ Previous Accidents } \\
\hline Yes & 53 & 18.03 & \\
\hline No & 239 & 81.29 & \\
\hline School Grade & & & $8.08(1.83)$ \\
\hline $6-7$ & 141 & 47.96 & \\
\hline $8-9$ & 67 & 22.79 & \\
\hline $10-11$ & 78 & 26.53 & \\
\hline 12 & 8 & 2.72 & \\
\hline \multicolumn{4}{|l|}{ Ethnic Background } \\
\hline European/ Caucasian & 243 & 82.65 & \\
\hline Asian & 29 & 9.86 & \\
\hline Other & 22 & 7.48 & \\
\hline \multicolumn{4}{|l|}{ License Status } \\
\hline No License & 251 & 85.37 & \\
\hline Learner License & 16 & 5.44 & \\
\hline Restricted License & 1 & 0.34 & \\
\hline Full Licence & 7 & 2.38 & \\
\hline
\end{tabular}


Table 2

ARBQ behaviour items means and standard deviation for Belgium, New Zealand, Spain and the UK

\begin{tabular}{|c|c|c|c|c|c|c|c|c|c|c|c|c|c|}
\hline No. & Item (How often do you...) & & elgium & & & Zeala & & & & & $\mathrm{Sp}$ & & \\
\hline & & $\mathrm{R}$ & M & SD & $\mathrm{R}$ & $\mathrm{M}$ & SD & $\mathrm{R}$ & M & SD & $\mathrm{R}$ & M & SD \\
\hline 40 & Look both ways before crossing & 1 & 4.31 & .96 & 1 & 4.17 & .95 & 1 & 4.08 & 1.07 & 1 & 4.07 & 1.08 \\
\hline 41 & $\begin{array}{l}\text { Check to make sure traffic has stopped before using a } \\
\text { pedestrian crossing }\end{array}$ & 2 & 3.87 & 1.05 & 2 & 3.73 & 1.15 & 2 & 3.46 & 1.30 & 2 & 3.76 & 1.15 \\
\hline 39 & $\begin{array}{l}\text { Keep looking and listening until you get all the way } \\
\text { across the road }\end{array}$ & 3 & 3.55 & 1.14 & 5 & 3.24 & 1.17 & 4 & 3.26 & 1.26 & 4 & 3.34 & 1.24 \\
\hline 42 & Use a crossing monitor where there is one available & 4 & 3.45 & 1.27 & 4 & 3.27 & 1.27 & 26 & 2.06 & 1.20 & 6 & 2.92 & 1.35 \\
\hline 9 & Cross at a place that is well lit when it is dark & 5 & 3.36 & 1.06 & 7 & 3.13 & 1.08 & 3 & 3.32 & 1.16 & 3 & 3.48 & 1.18 \\
\hline 37 & Use lights on your bike when it is dark & 6 & 3.11 & 1.53 & 15 & 2.64 & 1.53 & 5 & 2.84 & 1.62 & 19 & 2.37 & 1.56 \\
\hline 36 & Wear a cycle helmet when riding a bike & 7 & 3.07 & 1.59 & 3 & 3.70 & 1.40 & 27 & 2.03 & 1.40 & 26 & 2.03 & 1.41 \\
\hline 43 & Walk facing the traffic on roads without pavements & 8 & 2.97 & 1.17 & 10 & 2.89 & 1.19 & 12 & 2.51 & 1.36 & 17 & 2.51 & 1.23 \\
\hline 17 & Make traffic slow down or stop to let you cross & 9 & 2.85 & 1.19 & 24 & 2.22 & 1.05 & 15 & 2.43 & 1.24 & 14 & 2.66 & 1.14 \\
\hline 38 & Walk in single file on roads without pavements & 10 & 2.86 & 1.29 & 20 & 2.40 & 1.16 & 11 & 2.54 & 1.38 & 10 & 2.81 & 1.41 \\
\hline 14 & $\begin{array}{l}\text { Get part way across the road and then have to run the } \\
\text { rest of the way to avoid traffic }\end{array}$ & 11 & 2.74 & 1.04 & 9 & 3.01 & 1.04 & 6 & 2.82 & 1.14 & 8 & 2.88 & 1.04 \\
\hline 18 & $\begin{array}{l}\text { Cross from between parked cars when there is a safer } \\
\text { place to cross nearby }\end{array}$ & 12 & 2.70 & .99 & 11 & 2.88 & 1.03 & 9 & 2.66 & 1.16 & 7 & 2.92 & 1.07 \\
\hline 20 & $\begin{array}{l}\text { Not bother walking to a nearby crossing to cross the } \\
\text { road }\end{array}$ & 13 & 2.66 & 1.05 & 8 & 3.10 & 1.13 & 7 & 2.72 & 1.22 & 9 & 2.85 & 1.14 \\
\hline 5 & Cross from behind a stationary vehicle & 14 & 2.64 & 1.00 & 12 & 2.83 & 1.05 & 16 & 2.35 & 1.17 & 11 & 2.79 & 1.12 \\
\hline 4 & $\begin{array}{l}\text { Cross whether traffic is coming or not, thinking the } \\
\text { traffic should stop for you }\end{array}$ & 15 & 2.62 & 1.13 & 27 & 2.15 & 1.12 & 29 & 1.99 & 1.21 & 16 & 2.55 & 1.23 \\
\hline 6 & $\begin{array}{l}\text { Cross when you cannot see both ways very well (like } \\
\text { on a bend or a top hill). }\end{array}$ & 16 & 2.59 & 1.01 & 16 & 2.45 & .94 & 13 & 2.49 & 1.10 & 23 & 2.25 & .96 \\
\hline 10 & Not look because you cannot hear any traffic around & 17 & 2.58 & 1.17 & 14 & 2.65 & 1.16 & 21 & 2.25 & 1.22 & 15 & 2.59 & 1.23 \\
\hline 1 & $\begin{array}{l}\text { Forget to look properly because you are thinking about } \\
\text { something else }\end{array}$ & 18 & 2.57 & 1.08 & 15 & 2.47 & .99 & 14 & 2.44 & 1.08 & 18 & 2.46 & 1.01 \\
\hline 2 & $\begin{array}{l}\text { Forget to look properly because you are talking to } \\
\text { friends who are with you }\end{array}$ & 19 & 2.57 & 1.16 & 13 & 2.80 & 1.06 & 10 & 2.65 & 1.15 & 5 & 3.05 & 1.12 \\
\hline 16 & See a small gap in the traffic and "go for it" & 20 & 2.56 & 1.13 & 6 & 3.14 & 1.08 & 8 & 2.69 & 1.30 & 13 & 2.73 & 1.13 \\
\hline 7 & Cross without waiting for the "green man" & 21 & 2.50 & 1.23 & 18 & 2.42 & 1.23 & 17 & 2.35 & 1.17 & 12 & 2.79 & 1.12 \\
\hline 12 & Walk in the road rather than on the pavements & 22 & 2.45 & .96 & 19 & 2.41 & 1.00 & 23 & 2.22 & 1.07 & 21 & 2.29 & .96 \\
\hline 35 & $\begin{array}{l}\text { Wear bright or reflective clothing when riding a bike in } \\
\text { the dark }\end{array}$ & 23 & 2.22 & 1.38 & 30 & 1.95 & 1.26 & 35 & 1.79 & 1.24 & 31 & 1.78 & 1.23 \\
\hline 30 & Hang around in the road talking to friends & 24 & 2.19 & 1.12 & 17 & 2.43 & 1.15 & 20 & 2.27 & 1.23 & 29 & 1.90 & 1.00 \\
\hline 3 & Use a mobile phone and forget to look properly & 25 & 2.17 & 1.22 & 29 & 2.07 & 1.15 & 28 & 2.03 & 1.15 & 27 & 2.01 & 1.04 \\
\hline 13 & $\begin{array}{l}\text { Think it is ok to cross safely, but a car is coming faster } \\
\text { than you thought }\end{array}$ & 26 & 2.16 & .94 & 21 & 2.38 & .92 & 18 & 2.34 & 1.12 & 24 & 2.17 & .98 \\
\hline 32 & $\begin{array}{l}\text { Run around on the road (eg. When playing cricket or } \\
\text { football) }\end{array}$ & 27 & 2.14 & 1.16 & 25 & 2.21 & 1.14 & 22 & 2.24 & 1.29 & 30 & 1.80 & 1.04 \\
\hline
\end{tabular}




\begin{tabular}{|c|c|c|c|c|c|c|c|c|c|c|c|c|c|}
\hline 21 & $\begin{array}{l}\text { Not notice a car pulling out (say from a driveway) and } \\
\text { walk in front of it }\end{array}$ & 28 & 2.13 & .90 & 22 & 2.30 & 1.03 & 24 & 2.20 & 1.03 & 20 & 2.36 & 1.09 \\
\hline 27 & $\begin{array}{l}\text { Ride on a skateboard (or roller-skates/roller-blades) on } \\
\text { the road }\end{array}$ & 29 & 2.08 & 1.17 & 36 & 1.68 & 1.05 & 34 & 1.85 & 1.26 & 34 & 1.72 & 1.04 \\
\hline 15 & Have to stop quickly or turn back to avoid traffic & 30 & 2.06 & 91 & 23 & 2.23 & .94 & 19 & 2.34 & 1.07 & 22 & 2.27 & 1.01 \\
\hline 34 & Wear reflective clothing when out on foot in the dark & 31 & 2.00 & 1.22 & 32 & 1.69 & 1.04 & 36 & 1.67 & 1.07 & 35 & 1.58 & 1.00 \\
\hline 11 & $\begin{array}{l}\text { Climb over barriers or railings that separate the road } \\
\text { from the pavement }\end{array}$ & 32 & 1.91 & 1.05 & 31 & 1.94 & 1.09 & 30 & 1.97 & 1.21 & 28 & 1.95 & 1.08 \\
\hline 33 & Wear reflective clothing when crossing the road & 33 & 1.90 & 1.05 & 33 & 1.60 & .91 & 39 & 1.49 & .93 & 38 & 1.41 & .80 \\
\hline 31 & $\begin{array}{l}\text { Not notice an approaching car when playing games in } \\
\text { the road }\end{array}$ & 34 & 1.88 & .99 & 26 & 2.21 & 1.24 & 31 & 1.93 & 1.11 & 32 & 1.76 & .93 \\
\hline 19 & $\begin{array}{l}\text { Run across a road without looking because you are in a } \\
\text { hurry }\end{array}$ & 35 & 1.86 & .97 & 28 & 2.10 & 1.04 & 25 & 2.20 & 1.22 & 25 & 2.17 & 1.07 \\
\hline 29 & $\begin{array}{l}\text { Run into the road to get a ball, without checking for } \\
\text { traffic }\end{array}$ & 36 & 1.81 & .87 & 35 & 1.83 & .96 & 32 & 1.87 & 1.09 & 33 & 1.76 & .95 \\
\hline 8 & Cross less than an hour after drinking alcohol & 37 & 1.73 & 1.22 & 37 & 1.58 & .97 & 33 & 1.87 & 1.28 & 36 & 1.46 & .91 \\
\hline 28 & $\begin{array}{l}\text { Ride out into the road on a skateboard without thinking } \\
\text { to check for traffic }\end{array}$ & 38 & 1.57 & .90 & 38 & 1.36 & .73 & 38 & 1.50 & .95 & 39 & 1.31 & .71 \\
\hline 26 & Hold on to a moving vehicle when riding a bike & 39 & 1.48 & .87 & 39 & 1.36 & .82 & 41 & 1.36 & .89 & 37 & 1.42 & .92 \\
\hline 25 & $\begin{array}{l}\text { Hold on to a moving vehicle when riding a } \\
\text { skateboard/roller-skates/roller-blades }\end{array}$ & 40 & 1.47 & .85 & 40 & 1.35 & .81 & 40 & 1.38 & .91 & 41 & 1.24 & .68 \\
\hline 24 & $\begin{array}{l}\text { Deliberately run across the road without looking, for a } \\
\text { dare }\end{array}$ & 41 & 1.30 & .72 & 42 & 1.34 & .81 & 37 & 1.51 & .95 & 42 & 1.24 & .66 \\
\hline 23 & $\begin{array}{l}\text { Play "chicken" by deliberately running out in front of } \\
\text { traffic }\end{array}$ & 42 & 1.25 & .61 & 43 & 1.33 & .77 & 42 & 1.36 & .88 & 43 & 1.23 & .68 \\
\hline 22 & $\begin{array}{l}\text { Play "chicken" by lying down in the road and waiting } \\
\text { for cars to come along }\end{array}$ & 43 & 1.23 & .61 & 41 & 1.35 & .87 & 43 & 1.35 & .89 & 40 & 1.27 & .74 \\
\hline
\end{tabular}




\section{Table 3}

Summary of the CFA goodness-of-fit statistics for the ARBQ factor models $(n=292)$

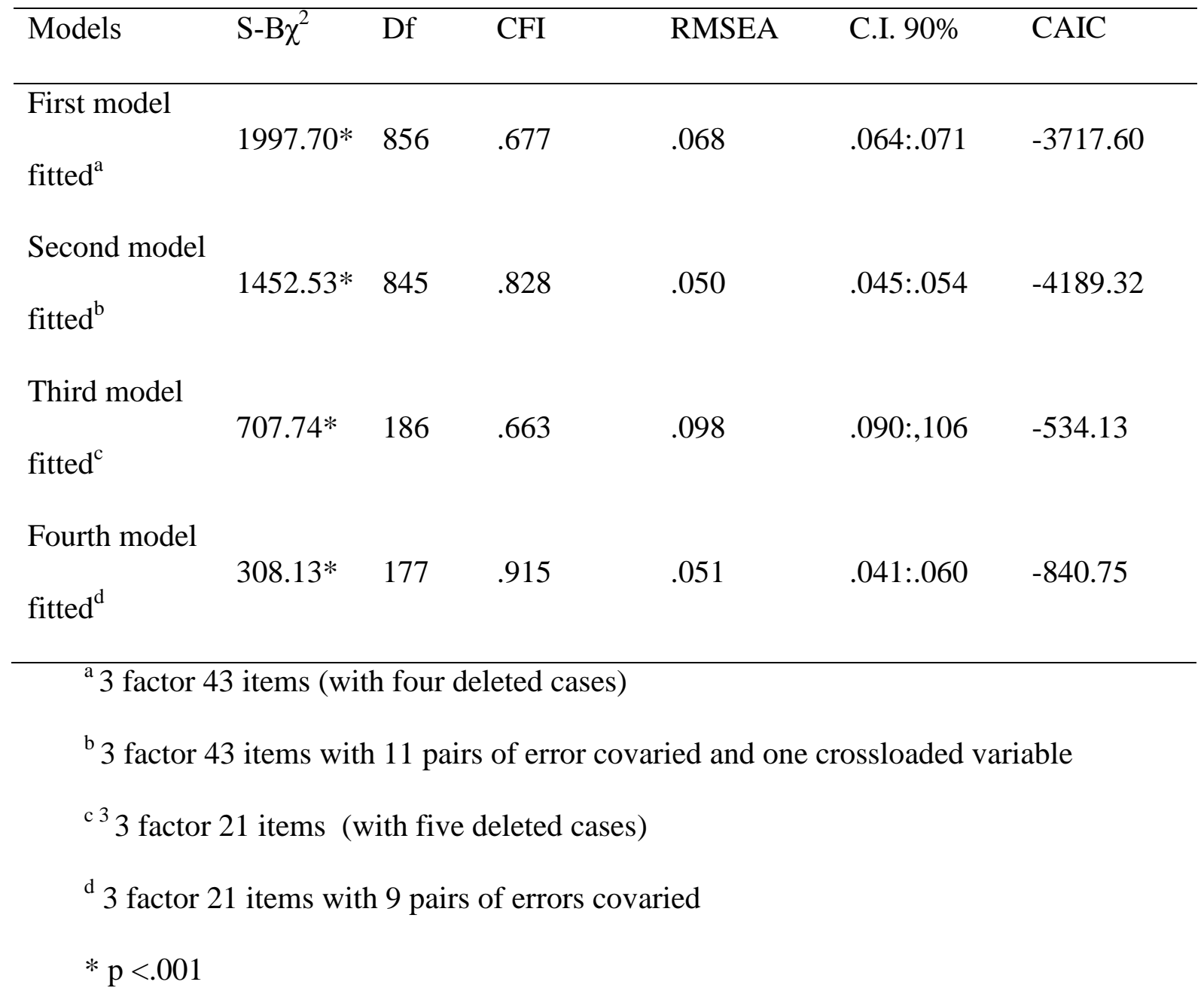




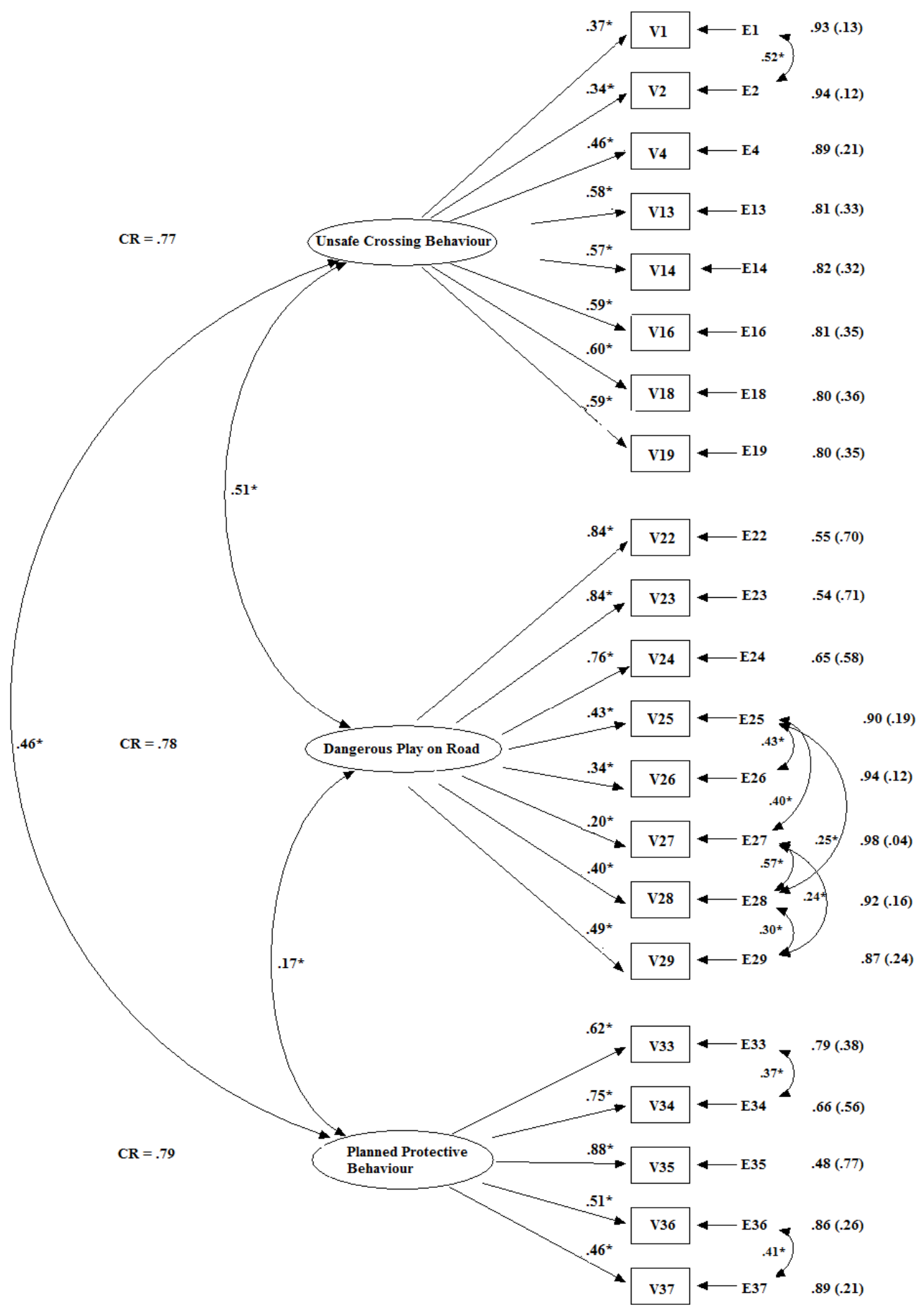

Figure 1: Confirmatory Factor Analysis of the ARBQ with Standardised factor loadings (rsquared); CR = Composite Reliability

$*$ significance $<.001$ 
Table 4

Adolescent Road-User Behaviour by gender

\begin{tabular}{lllll}
\hline & Males & Females & & \\
& Mean (SD) & Mean (SD) & t (292) & $\mathrm{p}$ \\
\hline Unsafe Crossing Behaviour & $2.63(.60)$ & $2.42(.62)$ & 2.92 & $<.001$ \\
Playing on Road & $1.64(.60)$ & $1.30(.43)$ & 3.98 & $<.01$ \\
Planned Protective & $2.37(1.00)$ & $2.55(.98)$ & 1.61 & $=.10$ \\
Behaviours (reversed) & & & & \\
\hline
\end{tabular}


Table 5

Adolescent Road-User Behaviour by Age

\begin{tabular}{|c|c|c|c|c|c|}
\hline & $\begin{array}{l}11-12 \text { years } \\
(\mathrm{N}=113)\end{array}$ & $\begin{array}{l}13-14 \text { years } \\
(\mathrm{N}=86)\end{array}$ & $\begin{array}{l}15 \text { and older } \\
(\mathrm{N}=95)\end{array}$ & & \\
\hline & Mean (SD) & Mean (SD) & Mean (SD) & $\mathrm{F}(2,291)$ & $\mathrm{p}$ \\
\hline $\begin{array}{l}\text { Unsafe crossing } \\
\text { behaviour }\end{array}$ & $2.31(.61)^{* a b}$ & $2.64(.67) *^{\mathrm{b}}$ & $2.68(.50) *^{a}$ & 11.61 & $<.001$ \\
\hline Playing on Road & $1.49(.47)$ & $1.66(.60) * a$ & $1.44(.54) * a$ & 4.46 & $<.01$ \\
\hline $\begin{array}{l}\text { Planned Protective } \\
\text { Behaviour } \\
\text { (reversed) }\end{array}$ & $3.02(.95) * a$ & $2.35(.94)^{* a}$ & $1.90(.69) * \mathrm{a}$ & 42.82 & $<.001$ \\
\hline
\end{tabular}


Table 6

Adolescent Road-User Behaviour by ethic group

\begin{tabular}{|c|c|c|c|c|c|}
\hline & $\begin{array}{l}\text { European } \\
(\mathrm{N}=243)\end{array}$ & $\begin{array}{l}\text { Asian } \\
(\mathrm{N}=29)\end{array}$ & $\begin{array}{c}\text { Other } \\
(\mathrm{N}=22)\end{array}$ & & \\
\hline & Mean (SD) & Mean (SD) & Mean (SD) & $\mathrm{F}(2,291)$ & $\mathrm{p}$ \\
\hline $\begin{array}{l}\text { Unsafe crossing } \\
\text { behaviour }\end{array}$ & $2.49(.60) *^{b}$ & $2.50(.63)$ *a $^{\mathrm{a}}$ & $2.92(.67)^{* a b}$ & 4.88 & $<.01$ \\
\hline $\begin{array}{l}\text { Playing on } \\
\text { Road }\end{array}$ & $1.49(.51)^{* a}$ & $1.55(.60)$ & $1.85(.68)^{* a \mathrm{a}}$ & 4.53 & $<.05$ \\
\hline Planned & $2.53(1.01)$ *a & $2.26(.81)$ & $1.96(.83)^{* a \mathrm{a}}$ & 4.00 & $<.05$ \\
\hline Protective & & & & & \\
\hline $\begin{array}{l}\text { Behaviour } \\
\text { (reversed) }\end{array}$ & & & & & \\
\hline
\end{tabular}

* reliable difference accounting for Bonferroni adjustment for multiple comparisons. 


\section{Table 7}

Factor structure of the Sensation Seeking Scale

\begin{tabular}{|c|c|c|c|}
\hline Items & $\begin{array}{l}\text { Item listings } \\
\end{array}$ & Factor 1 & Factor 2 \\
\hline 4 & $\begin{array}{l}\text { I am the sort of person who would find it exciting to do } \\
\text { risky sports }\end{array}$ & .700 & \\
\hline 2 & $\begin{array}{l}\text { I am the sort of person who would like to ride my bike } \\
\text { very fast down a hill }\end{array}$ & .619 & \\
\hline 1 & $\begin{array}{l}\text { I am the sort of person who would like to sled fast down } \\
\text { a steep hill. }\end{array}$ & .581 & \\
\hline 3 & $\begin{array}{l}\text { I wouldn't be afraid to climb to the very top of a tall } \\
\text { ladder }\end{array}$ & .552 & \\
\hline 5 & $\begin{array}{l}\text { I am the sort of person who would like to go on roller- } \\
\text { coasters and other fast rides }\end{array}$ & .470 & \\
\hline 6 & $\begin{array}{l}\text { I like to go to places where there are large crowds and } \\
\text { lots of excitement }\end{array}$ & .446 & \\
\hline 7 & $\begin{array}{l}\text { I am the sort of person who would like to go on vacation } \\
\text { to some exotic place in another part of the world }\end{array}$ & .368 & \\
\hline 18 & I sometimes like to do things that are a little scary & .753 & \\
\hline 20 & I would like to try surf-board riding & .737 & \\
\hline 21 & $\begin{array}{l}\text { I don't mind trying fun things that I'm not sure how to } \\
\text { do and that are a bit scary }\end{array}$ & .725 & \\
\hline 17 & I would like to try mountain climbing & .725 & \\
\hline 22 & $\begin{array}{l}\text { I would like to try jumping from a plane with a } \\
\text { parachute }\end{array}$ & .723 & \\
\hline 19 & I would like to try to water-ski & .703 & \\
\hline 24 & $\begin{array}{l}\text { I think it would be fun to ski really fast down a snowy } \\
\text { mountain }\end{array}$ & .697 & \\
\hline 25 & I like to jump or dive off a diving board & .610 & \\
\hline 27 & $\begin{array}{l}\text { I think it would be fun to sail on the ocean in a small } \\
\text { boat }\end{array}$ & .518 & \\
\hline 26 & I like to swim in deep water that is over my head & .492 & \\
\hline 23 & $\begin{array}{l}\text { I like to do tricks and try new things when riding my } \\
\text { bike, even if they could be a bit dangerous }\end{array}$ & .351 & \\
\hline 11 & $\begin{array}{l}\text { Even if I am doing something I enjoy, it is easy for me } \\
\text { to stop doing it when someone tells me it is time to stop }\end{array}$ & & .653 \\
\hline 9 & $\begin{array}{l}\text { If there is something fun that } \mathrm{I} \text { am not supposed to do, I } \\
\text { can usually stop myself from doing it }\end{array}$ & & .631 \\
\hline 12 & I usually think things through before I speak & & .574 \\
\hline 15 & $\begin{array}{l}\text { Even when I'm having a good time I don't mind leaving } \\
\text { to go home. }\end{array}$ & & .570 \\
\hline 14 & $\begin{array}{l}\text { It's not hard for me to wait my turn when playing, even } \\
\text { if I'm excited }\end{array}$ & & .556 \\
\hline 13 & $\begin{array}{l}\text { I usually don't peak at my presents before I get them, } \\
\text { even if I know where they are hidden. }\end{array}$ & & .547 \\
\hline 8 & I always wait my turn before I say an answer in class & & .544 \\
\hline 16 & I always finish a task once I make up my mind about it & & .514 \\
\hline 10 & Keeping secrets is easy for me & & .399 \\
\hline
\end{tabular}

Note: Items loading >.350 


\section{Table 8}

Mean differences in sensation seeking and ARBQ factors according to previous accident involvement

\begin{tabular}{|c|c|c|c|c|}
\hline & $\begin{array}{l}\text { Previous } \\
\text { accident/s } \\
(\mathrm{N}=53)\end{array}$ & $\begin{array}{c}\text { No previous } \\
\text { accident/s } \\
(\mathrm{N}=239)\end{array}$ & & \\
\hline & Mean (SD) & Mean (SD) & $\mathrm{t}$ & $\mathrm{p}$ \\
\hline Unsafe crossing behaviour & $2.78(.57)$ & $2.46(.62)$ & 3.50 & $<.001$ \\
\hline Playing on Road & $1.67(.60)$ & $1.49(.52)$ & 2.12 & $<.05$ \\
\hline $\begin{array}{l}\text { Planned Protective Behaviour } \\
\text { (reversed) }\end{array}$ & $2.16(.77)$ & $2.52(1.02)$ & -2.87 & $<.01$ \\
\hline Thrill Seeking Behaviour & $1.98(.62)$ & $2.34(.69)$ & -3.51 & $<.001$ \\
\hline Inhibition Behaviour & $2.84(.54)$ & $2.67(.60)$ & 1.87 & $=.06$ \\
\hline
\end{tabular}




\section{Table 9}

Pearson's Correlation between ARBQ factors, Sensation Seeking factors, age and accidents

\begin{tabular}{lcc}
\hline Age & $\begin{array}{c}\text { Thrill } \\
\text { Seeking }\end{array}$ & Inhibition Behaviours Accidents \\
&
\end{tabular}

\begin{tabular}{lllll}
\hline Planned Protective Behaviour & $-.47^{* *}$ & $.21^{* *}$ & $-.26^{* *}$ & $.14^{*}$
\end{tabular}

(reverse coded)

Playing on the road

$-.07 \quad-.38 * *$

$.33^{* *}$

$-.12 *$

Unsafe road crossing

$.23^{* *}-.31^{* *}$

$.39 * *$

$-.20 * *$

$* p_{p}<. \overline{01}$

$*_{p}<.05$

$(d f=294)$ 
Table 10

Sensation seeking by gender

\begin{tabular}{lllll}
\hline & $\begin{array}{l}\text { Males }(\mathrm{N}=148) \\
\text { Mean }(\mathrm{SD})\end{array}$ & $\begin{array}{l}\text { Females }(\mathrm{N}=146) \\
\text { Mean }(\mathrm{SD})\end{array}$ & $\mathrm{t}$ & $\mathrm{P}$ \\
\hline Thrill Seeking & $2.11(.73)$ & $2.45(.61)$ & -4.31 & $<.001$ \\
Inhibition Behaviour & $2.79(.60)$ & $2.61(.57)$ & 2.46 & $<.05$
\end{tabular}


Table 11

Sensation Seeking by Age

\begin{tabular}{llllll}
\hline & $\begin{array}{lllll}11-12 \text { years } \\
(\mathrm{N}=113)\end{array}$ & $\begin{array}{l}13-14 \text { years } \\
(\mathrm{N}=86)\end{array}$ & $\begin{array}{c}15 \text { and older } \\
(\mathrm{N}=95)\end{array}$ & & \\
& Mean $(\mathrm{SD})$ & Mean $(\mathrm{SD})$ & Mean $(\mathrm{SD})$ & $\mathrm{F}(2,291)$ & $\mathrm{P}$ \\
\hline Thrill Seeking & $2.38(.70)$ & $2.17(.74)$ & $2.25(.62)$ & 2.34 & $=.10$ \\
Inhibition & $2.59(.57)^{* \mathrm{a}}$ & $2.81(.67))^{* \mathrm{a}}$ & $2.74(.49)$ & 4.07 & $<.05$ \\
Behaviour & & & & & \\
\hline
\end{tabular}

* reliable difference accounting for Bonferroni adjustment for multiple comparisons. 
Table 12

Sensation seeking by ethic group

\begin{tabular}{llllll}
\hline & $\begin{array}{l}\text { European } \\
(\mathrm{N}=243)\end{array}$ & $\begin{array}{l}\text { Asian } \\
(\mathrm{N}=29)\end{array}$ & $\begin{array}{c}\text { Other } \\
(\mathrm{N}=22)\end{array}$ & & \\
& Mean (SD) & Mean $(\mathrm{SD})$ & Mean (SD) & $\mathrm{F}(2,291)$ & $\mathrm{p}$ \\
\hline Thrill seeking & $2.23(.65) *^{\mathrm{a}}$ & $2.62(.81)^{* \mathrm{a}}$ & $2.31(.85)$ & 4.06 & $<.05$ \\
$\begin{array}{l}\text { Inhibition } \\
\text { behaviour }\end{array}$ & $2.70(.61)$ & $2.64(.46)$ & $2.87(.53)$ & 1.14 & $=.35$ \\
\hline
\end{tabular}

* reliable difference accounting for Bonferroni adjustment for multiple comparisons. 